\title{
EVALUASI PELAKSANAAN TIGA PROGRAM POKOK USAHA KESEHATAN SEKOLAH (TRIAS UKS) DI SEKOLAH LUAR BIASA NEGERI 1 SLEMAN, YOGYAKARTA TAHUN 2016
}

\author{
Dara Puspita Lestari, Theresia Puspitawati, Choirul Anwar \\ Fakultas Ilmu Kesehatan Universitas Respati Yogyakarta \\ darapuspitalestari@gmail.com
}

\begin{abstract}
Abstrak
Kondisi kesehatan anak dengan disabilitas sangat kompleks, sehingga memerlukan pendekatan secara khusus dalam penanganannya. Mereka merupakan kelompok yang rentan, sehingga perlu ada upaya yang dilakukan untuk mengatasi hal tersebut. Salah satu upaya yang dapat dilakukan yaitu melalui program Usaha Kesehatan Sekolah. Namun, pada kenyataannya SLB merupakan salah satu sasaran UKS yang belum berjalan secara optimal. Sehingga apabila program UKS di SLB dapat diperbaiki, maka derajat kesehatan anak berkebutuhan khusus dapat meningkat.

Tujuan penelitian ini untuk mengevaluasi pelaksanaan tiga program pokok UKS di SLBN 1 Sleman Yogyakarta. Penelitian ini penelitian kualitatif, dengan desain atau rancangan studi kasus. Informan penelitian dalam penelitian ini adalah informan yang berkaitan dengan pelaksanaan TRIAS UKS di SLBN 1 Sleman Yogyakarta. Informan diambil menggunakan teknik penarikan sampel variasi maksimum (Maximum Variaton Sampling).

Hasil Penelitian adalah (1)Pendidikan kesehatan telah dilaksanakan dengan dilaksanakanya penyuluhan kesehatan dan pelatihan serta pembinaan. (2)Pelayanan kesehatan telah dilaksanakan diantaranya pemeriksaan kesehatan, UKGS untuk pemeriksaan gigi saja, P3K dan P3P serta imunisasi. (3)Pembinaan lingkungan sekolah sehat telah dilaksanakan dengan melakukan kegiatan kebersihan lingkungan sekolah, penataan halaman, melakukan penghijauan dan apotek hidup. Namun dalam pelaksanaannya masih terdapat beberapa aspek yang tidak sesuai dengan pedoman. Hal ini dipengaruhi beberapa hambatan yang terdiri dari SDM, Anggaran, Belum ada Petunjuk Teknis dan sarana serta prasarana yang belum lengkap. Dengan demikian Tiga program pokok UKS seluruhnya telah dilaksanakan oleh SLBN 1 Sleman, namun masih terdapat beberapa ketidaksesuaian dengan pedoman dikarenakan beberapa hambatan.
\end{abstract}

Kata Kunci: Evaluasi, TRIAS UKS, SLB

\section{Pendahuluan}

Anak merupakan salah satu sumber daya manusia di suatu negara, anak merupakan tunas, potensi, dan generasi penerus bangsa. Anak berkebutuhan khusus termasuk penyandang cacat juga merupakan salah satu sumber daya manusia bangsa Indonesia yang kualitasnya harus ditingkatkan agar dapat berperan, tidak hanya sebagai obyek pembangunan tetapi juga sebagai subyek pembangunan ${ }^{1}$.

Anak dengan disabilitas merupakan bagian dari anak Indonesia yang perlu mendapat perhatian dan perlindungan oleh pemerintah, masyarakat, dan keluarga sesuai dengan amanah dari Undang- 
Undang Nomor 4 Tahun 1997 tentang Penyandang Cacat, Undang- Undang Nomor 23 Tahun 2002 tentang Perlindungan Anak dan Undang-Undang Nomor 36 Tahun 2009 tentang kesehatan, sehingga upaya pelayanan kesehatan perlu dikembangkan untuk memberikan akses bagi anak dengan permasalahannya. Kondisi kesehatan anak dengan disabilitas sangat kompleks, terdiri dari berbagai macam jenis disabilitas dengan permasalahan yang cukup spesifik, sehingga memerlukan pendekatan secara khusus dalam penanganannya. Mereka merupakan kelompok yang rentan dan rawan terhadap paparan penyakit maupun ancaman kekerasan $^{2}$.

$$
\text { Organisasi }
$$

Kesehatan

Dunia (WHO) mengemukakan bahwa penyandang disabilitas merupakan kelompok minoritas terbesar di dunia, dimana $80 \%$ dari jumlah penyandang disabilitas di dunia berada di kalangan negara-negara berkembang dan anak- anak mengambil porsi sepertiga dari total penyandang disabilitas dunia $^{3}$. Data dari Bank Dunia (World Bank) diperkirakan 85 persen anak berkebutuhan khusus di seluruh dunia yang berusia di bawah 15 tahun terdapat di negara berkembang, lebih dari dua pertiga populasi tersebut terdapat di Asia ${ }^{4}$.

Menurut data Badan Pusat Statistik Nasional pada tahun 2007 di Indonesia terdapat 8,3 juta jiwa anak dengan disabilitas dari total populasi anak yaitu sebesar 82.840 .600 jiwa anak atau sekitar $\quad 10 \%$ Daerah Istimewa Yogyakarta (DIY) memiliki prevalensi disablilitas tertinggi kedua setelah Propinsi Bengkulu dengan persentase sebesar $3,89 \%$ yang mana nilai ini di atas nilai nasional yaitu sebesar $2,45 \%^{2}$.

Sementara data jumlah penyandang disabilitas yang masih termasuk kategori usia sekolah pada akhir tahun 2014 diketahui terdapat 9.096 anak berkebutuhan khusus (ABK) usia sekolah di DIY. Dari jumlah tersebut, yang telah dan sedang mengikuti pendidikan di SLB ada 4.782 siswa, sedang yang bersekolah di sekolah penyelenggara pendidikan inklusi ada 2.388 siswa. Sisanya, masih terdapat 1.926 ABK usia sekolah yang belum tertangani karena berbagai faktor 5 .

Oleh karena itu harus ada upaya yang dilakukan untuk mengatasi hal tersebut, salah satu upaya yang dapat dilakukan adalah dengan menyelenggrakan pembinaan kesehatan anak usia sekolah. Pembinaan kesehatan anak usia sekolah merupakan langkah strategis untuk menyiapkan sumber daya manusia yang berkualitas di masa depan. Dan salah satu upaya yang dapat dilakukan yaitu melalui program Usaha Kesehatan Sekolah (UKS) ${ }^{6}$.

SLB merupakan salah satu sasaran UKS yang belum berjalan secara optimal, diantaranya dari sisi sarana/ prasarana yang ada sebagian besar SLB di Indonesia saat ini belum memiliki sarana dan prasarana pelayanan kesehatan UKS yang memadai. Pelaksanaan UKS di SLB juga masih jauh tertinggal dibandingkan dengan pelaksanaan UKS di sekolah-sekolah umum .

Kabupaten Sleman merupakan Kabupaten dengan jumlah SLB terbanyak se-DIY, yaitu dengan jumlah sebanyak 29 SLB, dengan rincian terdiri dari 1 SLB negeri dan 28 SLB swasta. SLB Negeri 1 Sleman merupakan satusatunya SLB Negeri yang terdapat di wilayah Kabupaten Sleman dan telah melaksanakan UKS ${ }^{7}$.

Berdasarkan hasil studi pendahuluan yang telah Peneliti lakukan pada bulan November-Desember didapat hasil yang menjadi dasar pentingnya penelitian ini untuk dilakukan yaitu masih terdapat beberapa masalah dalam pelaksanaan TRIAS UKS di SLB diantaranya, untuk pihak SLBN 1 Sleman pelaksanaan UKS sudah berjalan walaupun belum terbentuk Tim Pelaksana UKS. SLBN 1 Sleman masuk ke dalam wilayah kerja Puskesmas Pakem, namun terdapat beberapa kendala yang ada dalam pelaksanaan TRIAS UKS diantaranya yaitu belum adanya Petunjuk Teknis (JUKNIS) 
serta Petunjuk Pelaksanan (JUKLAK) UKS, kurang SDM ahli serta sarana prasarana yang mendukung belum sepenuhnya tersedia. Dari masalah yang didapat dari hasil tersebut, maka peneliti ingin mengevaluasi bagaimana pelaksanaan UKS di SLB Negeri 1 Sleman, Yogyakarta.

\section{Metode Penelitian}

Penelitian ini adalah penelitian kualitatif, dengan desain atau rancangan studi kasus. Penelitian dilaksanakan di SLBN 1 Sleman Yogyakarta. Penelitian dilakukan pada bulan Juni-Juli 2016.

Informan dalam penelitian ini sebanyak 7 orang, terdiri dari pemegang program UKS di SLBN 1 Sleman, Pemegang Program UKS di Puskesmas Pakem, Tenaga Kesehatan di Puskesmas Pakem, Kepala Sekolah, 2 orang siswa SLBN 1 Sleman dan Pemegang Program UKS di DIKPORA Provinsi DIY.

Definisi Istilah:

1. Pendidikan Kesehatan

Definisi: Pendidikan kesehatan merupakan upaya memberikan bimbingan kepada peserta didik untuk meningkatkan pengetahuan kemampuan dan ketrampilan peserta didik dalam melaksanakan perilaku hidup dan sehat, maka harus menyelenggarakan kegiatan sosialisasi setiap tahun sehingga seluruh peserta didik terpapar materi kesehatan dan kesehatan lingkungan ${ }^{8}$.

2. Pelayanan Kesehatan

Definisi: Pelayanan kesehatan di sekolah dilaksanakan oleh Tim Kesehatan dari Puskesmas bekerjasama dengan guru dan kader kesehatan sekolah ${ }^{9}$.

3. Pembinaan Lingkungan Sekolah Sehat

Definisi: Bertujuan untuk mewujudkan lingkungan sehat di sekolah/ madrasah yang memungkinkan setiap warga di sekolah/ madrasah mencapai derajat kesehatan setinggi- tingginya dalalm rangka mendukung tercapainya proses belajar yang maksimal bagi setiap peserta didik 9 .

4. Hambatan

Definisi: Hambatan atau kendala menurut Kamus Besar Bahasa Indonesia adalah sebuah halangan, rintangan, mengahalangi atau mencegah pencapaian sasaran, kekuatan yang memaksa pembatalan pelaksanaan $^{10}$.

Jenis dan Cara Pengumpulan Data yang digunakan dalam penelitian ini adalah data primer dan sekunder. Pengumpulan data dilakukan dengan wawancara mendalam bebas terpimpin, observasi dan dokumentasi.

Dalam penelitian ini untuk menguji keabsahan data digunakan 4 uji yang terdiri dari uji kredibilitas yaitu menggunakan triangulasi sumber, uji transferabilitas dengan menggunakan uraian rinci, uji dependabilitas dilakukan dengan diaudit oleh pembimbing terhadap seluruh aktivitas peneliti dalam penelitian dan uji konfirmabilitas.

Data diolah dengan melakukan transkip, setelah data menjadi sebuah transkip dilanjutkan dengan proses koding dan ketegorisasi. Teknik analisis data dilakukan dengan tahapan analisis isi yaitu reduksi data, penyajian data dan penarikan kesimpulan.

\section{Hasil Penelitian dan Pembahasan}

\section{A. Pendidikan Kesehatan \\ 1. Penyuluhan kesehatan}

Kegiatan penyuluhan kesehatan sudah dilaksanakan, bekerja sama dengan pihak lain seperti Puskesmas Pakem dan Rumah Sakit PKU Muhammadiyah, materi penyuluhan yang pernah diberikan atau disampaikan kepada siswa diantaranya kesehatan makanan, kesehatan lingkungan, sanitasi, narkoba dan kesehatan reproduksi. Walaupun dengan frekuensi penyuluhan yang belum bisa secara rutin karena dipengaruhi faktor anggaran yang tersedia.

"Beberapa kali saja. Belum bisa 
rutin. Kalau dulu itu hanya beberapa kali, tentang pergaulan remaja, tentang kespro itu Cuma 1 sesi aja beberapa hari berturut-turut. Yang mengadakan dulu kita mendapat bantuan-bantuan itu, jadi pihak sekolah yang mendapatkan bantuan entah itu dari Jakarta entah itu dari Dinas Pendidikan Propinsi. Kita mengadakan nanti kita bekerjasama dengan unit kesehatan seperti Puskesmas Pakem yang kita rangkul dulu, PKU itu juga pernah Muhammadiyah itu yang mengisi. Materinya tentang kesehatan makanan, lingkungan, sanitasi, termasuk narkoba, tentang kesehatan reproduksi”.'(Informan 1)

Informan 4 menyatakan informasi yang serupa:

\section{"Pernah, Guru disini".}

Adapun informasi lain yang didapat terkait penyuluhan kesehatan:

"Sasarannya hanya SMP, SMA. Metodenya saat penyuluhan itu biasa ya, karena yang diikutkan anak-anak yang mampu. Jadi kayak anak tuna rungu kan tidak bisa mendengar ada guru pendampingnya"(Informan 1).

Dengan demikian untuk kegiatan dapat disimpulkan penyuluhan kesehatan telah dilaksanakan oleh SLBN 1 Sleman tapi tidak secara rutin, materi yang disampaikan menurut pedoman sudah diberikan sebagian kepada siswa, namun sasarannya masih belum sepenuhnya tercapai hanya baru kepada guru dan siswa yang mampu saja seharusnya tidak hanya kepada guru dan siswa, namun menurut pedoman orangtua siswa perlu diberikan penyuluhan kesehatan.

Metode yang digunakan sudah sesuai dengan pedoman yang ada bahwa dilakukan disesuaikan dengan kebutuhan, yaitu yang dilakukan pihak sekolah adalah menyertakan guru pendamping siswa saat penyuluhan berlangsung.

2. Pembinaan dan Pelatihan

Adapun pembinaan serta pelatihan yang dilaksanakan di SLBN 1 Sleman yaitu dengan mekanisme dilakukan pembinaan oleh DIKPORA Provinsi DIY kepada perwakilan guru di SLB. Guru yang telah diberikan pembinaan ataupun pelatihan akan memberikan pembinaan serta pelatihan kembali kepada guru yang lainnya yang tidak mendapatkan pembinaan serta pelatihan tersebut dan juga kepada siswa. Pelatihan serta pembinaan juga dilakukan pihak sekolah bekerjasama dengan pihak luar sekolah disesuikan dengan materi pembinaan ataupun pelatihan yang akan diberikan.

"Baru sebatas pelatihan ya, pelatihan ke guru-gurunya. Sesuai anggaran, anggarannya itu per tahun, setahun sekali kita bina pelatihan". (Informan 3)

Informasi serupa dinyatakan oleh informan 5:

"Pernah, tentang kalau ngobati luka kena peso atau kena apa pake obat ini, Cuma luka-luka itu aja".

Dengan demikian dapat disimpulkan bahwa SLBN 1 Sleman sudah melaksanakan pembinaan serta pelatihan, namun masih terdapat ketidaksesuaian yaitu yang menjadi sasaran pembinaan serta pelatihan belum sesuai dengan pedoman ${ }^{1}$ karena seharusnya pembinaan dan pelatihan diberikan kepada Tim Pelaksana UKS yang mana di dalamnya bukan hanya guru dan murid saja yang harus dibina serta dilatih, selain itu belum adanya kader kesehatan yang dibentuk oleh pihak SLBN 1 Sleman seperti dokter kecil.

B. Pelayanan Kesehatan

1. Pemeriksaan Kesehatan

Pelayanan kesehatan yang dilaksanakan dalam rangka pelaksanaan UKS di SLBN 1 Sleman berupa pemeriksaan kesehatan yang dilakukan dalam waktu satu bulan sekali. 
Pemeriksaan kesehatan dilakukan oleh RS PKU Muhammadiyah, dengan sebelumnya dilakukan kerjasama dengan pihak sekolah. dana pemeriksaan tersebut diperoleh sekolah dari Dinas Pendidikan Pemuda dan Olahraga Provinsi DIY. Namun demikian dana yang ada tidak selalu ada sehingga menyebabkan pelaksanaan pemeriksaan tersebut tidak dapat berjalan secara rutin dan sementara berhenti.

"Kalau pemeriksaan kesehatan itu, biasanya MOUnya untuk satu tahun tapi pemeriksaanya Satu bulan sekali, itu tuh ada dana dari Dinas Pendidikan Propinsi. Dana kan yang ngelola itu bagian tata usaha sini, terus habis itu kalau sekarang dananya belum ada yang tahun ini ya pemeriksaan kesehatannya sudah ngga ada lagi, yang psikologinya juga ada. Tim PKU sini, Tim PKU Muhammadiyah sini yang melaksanakan”. (Informan 1)

Informasi serupa dinyatakan informan 2:

"sebulan sekali, tapi itu kan nanti kami gini untuk karena sekolah negeri kan ada anggaran untuk tenaga medis, psikolog dan lain sebagainya. Itu harus ada MOU dulu. Hanya saja anggaran itu kan turun sesuai jadwal kan, jadwalnya biasanya bulan maret atau april itu baru turun, nah itu baru bisa berjalan".

Sehingga dapat disimpulkan untuk pemeriksaan kesehatan yang telah dievaluasi bahwa pemeriksaan telah dilaksanakan dengan waktu pelaksanaan yang sesuai ${ }^{1}$ yaitu sekali dalam sebulan, namun hal ini menjadi tidak sesuai lagi karena untuk sementara kegiatan pelayanan kesehatan di SLBN 1 Sleman saat ini sementara berhenti karena menunggu anggaran tersedia untuk melakukan kerjasama kembali dengan pihak RS. PKU Muhammadiyah.

\section{UKGS}

Kegiatan ini telah dilaksanakan pihak SLBN 1 Sleman dengan dilakukannya pemeriksaan gigi kepada siswa saat dilakukan juga pemeriksaan kesehatan secara umum yang dilakukan sekali dalam sebulan apabila sudah ada kerjasama untuk satu tahun dengan pihak RS. PKU Muhammadiyah.

"pemeriksaan yang kesehatan biasanya itu juga ada gigi”(Informan 1)

Informasi serupa diungkapkan oleh informan 2:

"sekalian semua pas pemeriksaan kesehatan itu".

Dengan demikian dapat disimpulkan bahwa untuk pelaksanaan UKGS di SLBN 1 Sleman belum dilaksanakan secara komprehensif pada tiga tahap UKGS menurut pedoman ${ }^{11}$ yang ada.

\section{3. $\mathrm{P} 3 \mathrm{~K}$ dan $\mathrm{P} 3 \mathrm{P}$}

Pelaksaan P3K telah dilakukan oleh guru apabila terjadi kecelakaan pada siswa di sekolah seperti terluka karena terjatuh upaya yang dilakukan adalah dengan melakukan pertolongan pertama seperti pembersihan dan pengobatan pada luka terhadap siswa yang bersangkutan, selain $\mathrm{P} 3 \mathrm{~K}$ adapun pelaksanaan P3P yang selama ini dilaksanakan oleh guru di SLBN 1 Sleman yaitu dengan memberikan penanganan pertama kepada siswa yang mengalami sakit sesuai kemampuan yang ada, jika penyakit yang tidak bisa ditangani oleh guru, maka siswa yang bersangkutan akan langsung drujuk ke puskesmas setempat atau RS. Pku Muhammadiyah.

"ada mba murid jatuh, langsung kita bersihkan lukanya dan kita obati, pernah ada murid sakit, kalau bisa ditangani seperti kejang, sakit kepala, pusing, pingsang dan apabila membutuhkan pertolongan lebih lanjut kita rujuk ke puskesmas atau PKU Muhammadiyah, tapi sering banyak kejadian lukanya atau sakitnya sudah dari rumah tapi tetap kita 
tangani"(Informan 1).

Informasi serupa disampaikan informan 2 sebagai berikut:

"Ya sebisanya kita, kalau seperti jatuh masih bisa diobati langsung diobati, kalau sakitnya tidak bisa ditangani ya perlu dirujuk".

lain $^{12}$. Dejalan dengan penelitian disimpulkan bahwa kegiatan P3P serta P3K dalam rangka pelaksanaan TRIAS UKS telah dilaksanakan oleh SLBN 1 Sleman adapun hal pendukung lain seperti peralatan serta obat-obatan penunjang kegiatan P3K serta P3P tersebut sudah lengkap hal ini sesuai dengan hasil observasi yang telah dilakukan peneliti.

\section{Imunisasi}

Untuk kegiatan imunisasi, pihak sekolah dalam pelaksanaanya dibantu pihak Puskesmas setempat yaitu Puskesmas Pakem. Informasi ini didapat dari hasil wawancara

mendalam bersama informan 1 sebagai berikut:

"Kalau kita imunisasi ikut BIAS dari Puskesmas Pakem”.

Informasi tersebut didukung oleh informasi dari informan 6 dan 7:

"Kalau pelayanan kesehatannya yang sudah masuk di SLB itu yang BIAS, itu rutin setiap bulan BIAS itu semua tercover. Dengan Tim Puskesmas sesuai jadwal".

"Ya, namun diskrining dulu. Apakah anak ini dari pemeriksaan fisik bisa diberikan imunisasi atau tidak, untuk penapisan awal. Misalnya kalau imunisasi DT itu dia sedang panas atau tidak, atau dia mempunyai riwayatriwayat penyakit yang tidak boleh diberikan imunisasi ya kita tidak memberikan".

Dengan demikian pelaksanaan imunisasi sudah sesuai pedoman ${ }^{1}$.

\section{Pembinaan Lingkungan Sekolah Sehat \\ Pembinaan lingkungan sekolah} sehat sudah dilaksanakan oleh pihak sekolah dengan berbagai kegiatan diantaranya penghijauan, penataan halaman, pembuatan apotek hidup dan menjaga kebersihan lingkungan sekolah.

"Kalau lingkungan sehat itu dulu itu ada ini seperti ada penanaman hijauhijauan itu juga bantuan, seperti penanaman pohon-pohon banyak itu terus aliran-aliran air ini itu juga, penataan-penataan tumbuhan, ada apotek hidup juga”. (Informan 1)

Informasi tersebut didukung informasi dari informan lain:

"Jadwal piket bersihin kelas, pernah kerja bakti" (Informan 5).

Dengan demikian untuk pembinaan lingkungan sekolah sehat di SLBN 1 Sleman dalam rangka pelaksanaan TRIAS UKS sudah dilaksanakan hampir seluruh kegiatan dalam pedoman ${ }^{1}$ telah dilaksanakan.

D. Hambatan

Hambatan yang ditemui dalam penelitian ini terkait pelaksanaan UKS di SLBN 1 Sleman sebagai berikut:

1. Sumber Daya Manusia (SDM) yang dimaksud adalah Tim Pembina dan Tim Pelaksana UKS yang belum terbentuk dikarenakan belum terjalinnya kerja sama antara pihak DIKPORA Provinsi dengan sektorsektor lain yang terkait serta pihak sekolah itu sendiri dan SDM yang ada belum memiliki kemampuan untuk menangani kesehatan Anak Bekebutuhan Khusus.

2. Anggaran tersedia hanya dari APBD Provinsi

3. Petunjuk Teknis Pelaksanaan UKS yang belum dibuat

4. Sarana serta Prasarana belum terlengkapi seluruhnya. 
"hambatannya belum ada tim pelaksananya, belum ada saya hanya kemarin itu ditunjuk saja, jadi saya kira nanti kalau ada tim pelaksananya insyaallah jalan, hambatannya itu termasuk dana itu juga kan perlatan juga kan butuh dana”. (Informan 1)

Informan 3 mengungkapkan informasi sebagai berikut:

"Selama ini masih dari APBD, kalau dari pusat belum ada, kalau dari pusat pun itu hanya semacam bantuan itupun hanya untuk satu atau dua sekolah".

Hambatan serupa ditemui pada survey cepat yang dilakukan oleh Kementerian Kesehatan RI ${ }^{1}$ di 6 SLB pada 3 Provinsi.

\section{Kesimpulan Dan Saran}

A. Kesimpulan

1. Pendidikan Kesehatan

Pendidikan kesehatan dalam rangka pelaksanaa TRIAS UKS telah dilaksanakan oleh SLBN 1 Sleman dengan dilakukanya kegiatan yang terdiri dari penyuluhan kesehatan dan pembinaan serta pelatihan. Namun, kegiatan tersebut tidak dapat dilakukan secara rutin dikarenakan dana yang tersedia. Selain itu masih terdapat ketidaksesuaian dalam pelaksanaan pendidikan kesehatan menurut pedoman yang ada yaitu diantaranya yang menjadi sasaran penyuluhan dan pembinaan serta pelatihan belum sesuai.

2. Pelayanan Kesehatan

Pelayanan kesehatan yang dilaksanakan di SLBN 1 Sleman dalam rangka pelaksanaan TRIAS UKS sebagian besar sudah dilaksanakan, namun masih ada kegiatan yang belum terlaksana secara komprehensif adalah UKGS dan kegiatan ini dapat berjalan apabila ada dana yang tersedia dari DIKPORA Provinsi DIY

3. Pembinaan Lingkungan Sekolah Sehat Pembinaan Lingkungan sekolah sehat dalam rangka pelaksanaan TRIAS UKS sudah dilaksanakan di SLBN 1
Sleman. Kegiatan tersebut terdiri dari melakukan kegiatan kebersihan sekolah dengan melakuan kerja bakti dan membuat jadwal piket setiap kelas, melakukan penataan halaman, melakukan perindangan atau penghijauan dengan menanam pohon di lingkungan sekolah, dan juga dibuatnya apotek hidup.

4. Hambatan
a. SDM
b. Anggaran
c. Petunjuk Teknis
d. Sarana Prasarana

B. Saran

1. Bagi Dinas Pendidikan, Pemuda dan Olahrga Provinsi DIY

Meningkatkan kerja sama lintas sektor dalam rangka membentuk Tim Pembina UKS di SLB dengan melibatkan berbagai sektor terkait, seperti kesehatan dan sektor lainnya yang mendukung, agar pelaksanaan UKS di SLB dapat dijalankan secara optimal melalui pembinaan yang terorganisasi dengan sistem monitoring serta evaluasi yang baik. Selain itu, perlu dibuatnya pedoman khusus untuk pelaksanan UKS di SLB sepeti petunjuk teknis dan petunjuk pelaksanaan, agar pelaksanaan UKS di SLB dapat dilaksanakan sesuai dengan pedoman yang ada.

2. Bagi Dinas Kesehatan DIY dan Kabupaten

Dinas Kesehatan DIY untuk menjalin koordinasi bersama dinas terkait lainnya untuk membentuk Tim Pembina di Tingkat Provinsi serta membuat pedoman pelaksanaan UKS khusus di SLB sesuai kebidangannya masingmasing.

Bagi Dinas Kesehatan Kabupaten untuk membentuk Tim Pembina di Tingkat Kabupaten dengan melakukan koordinasi bersama dinas terkait lainnya dan membantu melakukan pembinaan kepada Puskesmas setempat agar dapat melaksanakan UKS di SLB yang berada di wilayah kerjanya masing-masing sesuai kebidangannya.

3. Bagi Pihak Terkait 
Bagi pihak terkait lainnya yang memiliki tanggungjawab terhadap pelaksanaan UKS di SLB diharapkan untuk membantu memfasilitasi jalannya pelaksanaan Program UKS di SLB baik dari segi anggaran, maupun sarana serta prasarana.

4. Bagi Sekolah Luar Biasa Negeri 1 Sleman Yogyakarta

Untuk membentuk Tim Pelaksana UKS dengan melibatkan unsur yang terdiri atas unsur pemerintahan desa/ kelurahan, Kepala Sekolah, Guru, Siswa, Puskesmas, Orang tua murid serta unsur lain yang relevan dan meningkatkan sistem monitoring serta evaluasi khususnya dalam pelaksanaan UKS di SLBN 1 Sleman.

\section{Bagi Puskesmas Pakem}

Untuk bekerja sama secara terorganisasi atau terstruktur dengan SLBN 1 Sleman, kaitannya untuk membentuk Tim Pelaksana UKS di SLBN 1 Sleman agar pelaksanaan UKS di SLBN 1Sleman dapat berjalan optimal sesuai dengan pedoman yang ada dan diharapkan dapat

mengembangkan program yang inovatif terkait dengan Pelaksanaan UKS di SLB..

6. Bagi Universitas Respati

Menambah referensi kepustakaan berkaitan dengan pelaksanaan UKS di SLBN 1 Sleman yang dapat dijadikan sebagai acuan untuk mengembangkan penelitian dan kajian ilmiah mahasiswa, sehingga dapat memberi manfaat kepada masyarakat.

7. Bagi Peneliti Selanjutnya

Diharapkan dapat mengembangkan penelitian tentang pelaksanaan UKS di SLB dengan sudut pandang yang berbeda, seperti dalam hal perencanaan ataupun program UKS secara keseluruhan yang dilaksanakan di SLB, dapat juga menggunakan metode penelitian serta informan penelitian yang berbeda.

\section{Daftar Referensi}

Direktorat Jenderal Bina Kesehatan Masyarakat, Direktorat Bina Kesehatan Anak, KEMENKES RI. Pedoman
Pelayanan Kesehatan Anak di Sekolah Luar Biasa (SLB) Bagi Petugas Kesehatan, 2010.

Kementerian Kesehatan RI. (2014). Situasi Penyandang Disabilitas. Buletin Jendela Data dan Informasi Kesehatan, Semester II.

Kementerian Kesehatan RI. (2014). Infodatin Pusat Data dan Informasi Kementerian Kesehatan RI, Penyandang Disabilitas Pada Anak.

Chamidah, A. N. (2010). Pendidikan Inklusif Untuk Anak Dengan Kebutuhan Kesehatan Khusus. Jurnal Pendidikan Khusus, Vol. 7. Nomor 2. Hlm. 64-71.

Hidayah, N. (2015). “Kebijakan Pemerintah Daerah Istimewa Yogyakarta Dalam Upaya Meningkatkan Pemenuhan Hak Pendidikan Penyandang Disabilitas Menurut Perda DIY Nomor 4 Tahun 2012 Tentang Perlindungan dan Pemenuhan Hak-Hak Penyandang Disabilitas". Skripsi. Universitas Islam Negeri Sunan Kalijaga.

Muzakkiroh, U., Suparmanto, P., Pranata, S. \& Wardani, Y. F. 2004. Kemitraan Antara Puskesmas Dengan Sekolah Dasar Dalam Kegiataan Usaha Kesehatan Sekolah (UKS), Studi Kasus Di Wilayah Kerja Puskesmas Jabon, Kecamatan Jombang, Kabupaten Jombang Jawa Timur, Tahun 2004. Buletin Penelitian Sistem Kesehatan. Vol.8, No. 2.

Admin. (2015). Internet. Daftar Nama dan Alamat Sekolah di DIY. http://www.pendidikan-diy.go.id/, diakses pada 05 November 2015.

Afandi, L. (2012). "Pelaksanaan Program Usaha Kesehatan Sekolah Di SD Negeri Se-Kecamatan Samigaluh Kabupaten Kulonprogo". Skrpsi. Universitas Negeri Yogyakarta.

Kementerian Pendidikan Dan Kebudayaan Direktorat Jenderal Pendidikan Dasar. (2012). Pedoman Pembinaan dan Pengembangan Usaha Kesehatan Sekolah. Jakarta. 
Admin. (2012). Internet. Hambatan (Kamus Besar Bahasa Indonesia). http://kamus.sabda.org/kamus/hambata n, diakses pada 07 Januari 2016.

Kementerian Kesehatan RI. (2012). Pedoman Usaha Kesehatan Gigi Sekolah. Jakarta.

Martunus. (2013). Peran Pelaksana Usaha Kesehatan Sekolah Dalam Kesehatan Anak SD Negeri No.026 Simpang Tiga Kecamatan Loan Janan Ilir. eJournal Ilmu Sosiatri, Volume 1, No 2, Hlm. 51-64. 